\title{
Enzymatic Determination of Phosphatidylcholine, Sphingomyelin and Phosphatidylglycerol in Lipid Dispersions, Blood Cell Membrames and Rat Pulmonary Surfactant ${ }^{1}$ )
}

\author{
José A. Encinar ${ }^{1}$, María-D. Ludeña ${ }^{2}$, Jesús Sánchez-Yagüe ${ }^{1}$ and Marcial Llanillo ${ }^{1}$ \\ 1 Departamento de Bioquímica y Biología Molecular \\ 2 Departamento de Biología Celular y Patología \\ Universidad de Salamanca, 37007 Salamanca, Spain
}

\begin{abstract}
Summary: A new micromethod for the determination of sphingomyelin in samples suspended in aqueous solutions, and modified micromethods for determining phosphatidylcholine and phosphatidylglycerol were used to determine phosphatidylcholine and sphingomyelin (detection limits of $1.8 \mu \mathrm{mol} / \mathrm{l}$ ), and phosphatidylglycerol (detection limit of $2.3 \mu \mathrm{mol} / \mathrm{l}$ ) in lipid dispersions, membranes from sheep erythrocytes and platelets, and pulmonary surfactants from rats of different ages and rats maintained under normobaric hyperoxia for 2 days prior to their sacrifice. The procedures are easy to perform, accurate, require less sample than conventional methods and can also be applied directly to aqueous samples. Phospholipase $\mathrm{C}$ and sphingomyelinase were used to release phosphorylcholine from phosphatidylcholine and sphingomyelin, respectively. The choline released from phosphorylcholine by alkaline phosphatase is reconverted to phosphorylcholine by ATP and choline kinase. In the phophatidylglycerol determination, phospholipase D was used to release glycerol and phosphatidate. The glycerol formed was converted to glycerolphosphate using ATP and glycerol kinase. In all cases, the ADP thus formed was determined by following the enzymatic conversion of NADH to NAD at $340 \mathrm{~nm}$ in an coupled pyruvate kinase/lactate dehydrogenase system. Significant variations in the phospholipid composition of rat pulmonary surfactant were found during development; in particular there was an increase in the phosphatidylglycerol content of adult rats as compared with younger rats. Hyperoxia produced changes in the phosphatidylglycerol content of surfactant from adult rats, but not from 2-day old rats.
\end{abstract}

\section{Introduction}

Phospholipids are known to have several important biological functions, especially as structural components of membranes, as storage and transport forms of metabolic fuel, and as constituents of signal transduction pathways (1). Phospholipids also play an important role as lung surfactant (2). Precise determination of the major phospholipids is important in biochemistry, food chemistry and clinical chemistry. Diagnostic applications include the quantification of phosphatidylcholine, sphingomyelin and phosphatidylglycerol in amniotic fluid from women with "at-risk" pregnancies for the assessment of fetal lung maturity. A phosphatidylcholine/sphingomyelin ratio of 2 or greater has been reported to be indicative of fetal lung maturity (3). Measurements of this ratio as well as the phosphatidylglycerol contents in amniotic fluid afford even greater realibility in the prediction of fetal lung maturation in normal and complicated pregnancies, because phosphatidylglycerol, together with

\footnotetext{
1) Funding organization:

Fondo de Investigaciones de la Seguridad Social (FISS), Spain, (grant \# 93/0737 to M.D.L.).
}

phosphatidylcholine, is critical for alveolar stability, and its absence may precipitate respiratory distress syndrome in newborns (3). Other diagnostic applications of phospholipid determination are the detection of changes in surfactant composition associated with certain types of lung injury (4), or the diagnosis of hyperlipoproteinaemia (5).

Currently, numerous methods for the estimation of phospholipids in body fluids and other biological materials are available. The most frequently used involves the separation of different classes of phospholipids by TLC and their quantification by densitometry or by measuring the phosphorus content of each phospholipid (6-11). Accurate phospholipid values can also be obtained with the aid of HPLC $(12,13)$. However, although the resolving powers for phospholipids are good, the absolute values for individual phospholipid species largely depend on the methods used for their detection (14). Moreover, all the non-enzymatic methods described above require extraction with organic solvents before further analysis, a step that can lead to relatively poor precision. They are also tedious, time-consuming and use more sample than enzymatic methods, sometimes requiring highly sophis- 
ticated instrumentation. On the other hand, enzymatic assays avoid the extraction step. Several enzymatic methods for the determination of phosphatidylcholine, sphingomyelin and phosphatidylglycerol concentrations mainly in amniotic fluid, have now been developed $(15-19)$.

The goal of the present work was to develop enzymatic methods for determining phosphatidylcholine, sphingomyelin and phosphatidylglycerol concentrations in cell membranes and lipid dispersions from sheep erythrocytes and platelets, and use them to study the phospholipid composition of pulmonary surfactant from rats of different ages, and rats maintained under hyperoxia prior to sacrifice.

\section{Materials and Methods}

Reagents

ATP (disodium, grade I), bovine serum albumin, choline kinase ${ }^{2}$ ) (from baker's yeast), NADH (disodium salt), phosphorylcholine calcium chloride, phosphoenolpyruvate tri(cyclohexylammonium) salt, phospholipase $\mathrm{C}^{2}$ ) (from Bacillus cereus, type XI), phospholipase $D^{2}$ ) (from Streptomyces species, type VII), sphingomyelin (from bovine brain), synthetic dipalmitoyl-sn-glycero-3-phosphocholine, synthetic dipalmitoyl-sn-glycero-3-phosphoglycerol and Triton X-100 were purchased from Sigma Chemical Co., St. Louis, MO 63178, USA. Glycerol kinase ${ }^{2}$ ) (from Candida mycoderma), pyruvate kinase $\mathrm{e}^{2}$ /lactate dehydrogenase ${ }^{2}$ ) (from rabbit muscle), alkaline phosphatase ${ }^{2}$ ) (from calf intestine) and sphingomyelinase ${ }^{2}$ ) (from Bacillus cereus) were from Boehringer Mannheim (Barcelona. Spain). Other products (analytical grade) and all organic solvents (high quality and glass-distilled twice) were purchased from Panreac, E-08110 Montcada i Reixac (Barcelona, Spain).

\section{Equipment}

The following equipment was used. Lyophilizer Flexi-Dry, model FDX 1-54 (FTS Systems Inc., 12484 NY, USA). Sonifier Cell Disrupter, model B-30 (Branson Sonic Power Co., Vésenaz-Genéve, $\mathrm{CH}-1222$ ). Spectrophotometer Hitachi, model U-2000 (Hitachi Ltd., Tokyo, Japan). Waterbath, model TFB-3 (SBS Instruments S. A., Badalona, Barcelona, Spain). Ultracentrifuge IEC, model B60 (Damon/IEC Division, 02194 MA, USA). A laboratory centrifuge and other materials used frequently in a biochemistry laboratory.

\section{Samples}

Isolation of blood cells and blood cell membranes

Platelets were isolated from freshly collected blood of adult sheep as indicated by Sánchez-Yagüe et al. (20). Platelet membranes were isolated from platelet homogenates obtained as described previously (20), by centrifugation at $100000 \mathrm{~g}$ for $1 \mathrm{~h}$ and resuspension in distilled water. Sheep erythrocytes were isolated under the conditions indicated by Marin et al. (21). Red blood cell mem-

\section{2) Enzymes:}

Calf intestine alkaline phosphatase (EC 3.1.3.1)

Baker's yeast choline kinase (EC 2.7.1.32)

Candida nycoderma glycerol kinase (EC 2.7.1.30)

Rabbit muscle lactate dehydrogenase (EC 1.1.1.27)

Bacillus cereus phospholipase C (EC 3.1.4.3)

Streptomyces species phospholipase D (EC 3.1.4.4)

Rabbit muscle pyruvate kinase (EC 2.7.1.40)

Bacillus cereus sphingomyelinase (EC 3.1.4.12). branes were obtained by hypotonic lysis of sheep packed erythro-

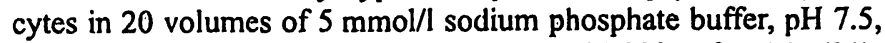
at $4{ }^{\circ} \mathrm{C}$ for $5 \mathrm{~min}$ and centrifugation at $100000 \mathrm{~g}$ for $1 \mathrm{~h}(21)$. Erythrocyte membrane pellets were washed once under the same conditions, and finally resuspended in distilled water.

\section{Lipid dispersions}

Total lipids from whole platelets were extracted according to the method of Bligh \& Dyer (22) as described previously (23). Total lipids from sheep erythrocytes were obtained by the method of Rose \& Oklander (24), as described previously (21). Total extracted lipids were dissolved in chloroform/methanol $(2+1$, by vol., $25 \mathrm{~g} / \mathrm{l}$ ). Lipid samples from standards, erythrocytes $(5 \mathrm{mg}$ of lipid phosphorus) or platelets (2 $\mathrm{mg}$ of lipid phosphorus) were dried under a nitrogen stream followed by evacuation, and hydration with $1 \mathrm{ml}$ of distilled water containing $12 \mathrm{~g} / \mathrm{l}$ Triton X-100. Lipid dispersions were prepared by vortexing the mixture for $3 \mathrm{~min}$ and sonicating at $0^{\circ} \mathrm{C}$ under a nitrogen stream in a sonifier cell disrupter set at 7 , for $10 \mathrm{~min}$ in intervals of $30 \mathrm{~s}$, followed by $30 \mathrm{~s}$ of recooling. The dispersed lipid suspensions were centrifuged at $4000 \mathrm{~g}$ for $45 \mathrm{~min}$. Supernatants were removed and stored under a nitrogen atmosphere at $4{ }^{\circ} \mathrm{C}$ until use.

\section{Isolation of pulmonary surfactant}

Surfactant was isolated from Wistar rats of different ages: newborns $(5-6 \mathrm{~h}$ old, $5.9 \pm 0.6 \mathrm{~g}), 2$ days old $(8.3 \pm 0.7 \mathrm{~g}), 7$ days old $(9.5 \pm 0.7 \mathrm{~g})$, and adults (90-120 days old, $175 \pm 25 \mathrm{~g})$. In other experiments, 2 days old or adult rats were placed in polystyrene chambers, and maintained in a $95-99.5 \% \mathrm{O}_{2}$ atmosphere for $48 \mathrm{~h}$. Control animals were exposed to air in identical chambers. Following an intraperitoneal injection of sodium pentobarbital, the tracheas were cannulated and the lungs were lavaged 4 times with maximal expansion using $9 \mathrm{~g} / 1 \mathrm{NaCl}$ at room temperature. Tracheal aspirates were obtained during routine aspiration. Aspirates from five animals were collected together in the case of non-adult rats, whereas individual tracheal aspirates were obtained from each adult animal. These aspirates were then centrifuged at $300 \mathrm{~g}$ for 20 min to remove cells and cell debris and the supernatants (surfactants) were dialysed for $48 \mathrm{~h}$ at $4{ }^{\circ} \mathrm{C}$ against distilled water with changes every $16 \mathrm{~h}$. The dialysed surfactants were stored at $-80^{\circ} \mathrm{C}$ under a nitrogen atmosphere until used. In the case of adults, surfactants were previously lyophilized, stored at $-80^{\circ} \mathrm{C}$, and resuspended in $1.5-2 \mathrm{ml}$ of distilled water when used. The protocols followed in the experimental procedures with the animals were in accordance with the guidelines of the Guide to the Care and Use of Experimental Animals, which is routinely used at our laboratory.

\section{Methods}

\section{Phosphatidylcholine determination}

This procedure is based on the method of Schiefer \& Beutler for quantifying phosphatidylcholine in amniotic fluid (17). The amount of phosphatidylcholine present in an aqueous sample is equivalent to the amount of NADH consumed in the reaction, which is followed by a decrease in absorbance at $340 \mathrm{~nm}$. Briefly, hydrolysis of phosphatidylcholine was carried out in an assay system (1.04 $\mathrm{ml}$ ) containing $140 \mathrm{mmol} / \mathrm{l}$ sodium borate buffer, $\mathrm{pH} 8.0 ; 5.5$ $\mathrm{mmol} / 1 \mathrm{MgSO}_{4} ; 5.77 \mathrm{~g} / \mathrm{l}$ of Triton X-100; $9611 \mathrm{U} / \mathrm{l}$ of phospholipase $\mathrm{C} ; 4230 \mathrm{U} / \mathrm{l}$ of alkaline phosphatase and sample or standard up to $0.4 \mathrm{ml}$. The mixture was incubated for $20 \mathrm{~min}$ at $37^{\circ} \mathrm{C}$. The reaction was then stopped by immersion in boiling water for at least $5 \mathrm{~min}$ and then cooled to room temperature. The choline released was subsequently determined by the addition of $60 \mu \mathrm{l}$ of an assay system containing $4.9 \mathrm{mmol} / \mathrm{NADH} ; 19.6 \mathrm{mmol} / \mathrm{l} \mathrm{ATP}$; $41.4 \mathrm{mmol} / \mathrm{l}$ phosphoenolpyruvate; $55 \mathrm{mmol} / \mathrm{l}$ glucose; $50 \mathrm{kU} / \mathrm{l}$ of pyruvate, kinase, and $50 \mathrm{kU} / \mathrm{l}$ of lactate dehydrogenase. The final mixture was shaken vigorously and then centrifuged at $700 \mathrm{~g}$ for $10 \mathrm{~min}$. The supernatant $(0.75 \mathrm{ml})$ was. read at $340 \mathrm{~nm}\left(\mathrm{~A}_{1}\right)$; a solution $(2.5 \mu \mathrm{l})$ containing $16 \mathrm{kU} / \mathrm{l}$ of ycholine kinase was then added and incubated at room temperature for $30 \mathrm{~min}$, and the absorbance of the mixture was read again at $340 \mathrm{~nm}\left(\mathrm{~A}_{2}\right)$. 


\section{Sphingomyelin determination}

This procedurc was carried out by measuring the choline released from sphingomyelin using a modification of the method described above for phosphatidylcholine determination. The amount of sphingomyelin present in an aqueous sample is equivalent to the amount of NADH consumed in the reaction, determined from the decrease in absorbance at $340 \mathrm{~nm}$. Sphingomyelin was hydrolysed in an aqueous system $(1.04 \mathrm{ml})$ containing $140 \mathrm{mmol} / \mathrm{l}$ sodium borate buffer, $\mathrm{pH} 8.0 ; 5.5 \mathrm{mmol}^{1} \mathrm{MgSO}_{4} ; 5.77 \mathrm{~g} / \mathrm{l}$ of Triton X-100; 9611 $\mathrm{U} / \mathrm{l}$ of sphingomyelinase; $4230 \mathrm{U} / \mathrm{l}$ of alkaline phosphatase and sample or standard up to $0.4 \mathrm{ml}$. The mixture was incubated for $2 \mathrm{~h}$ at $37^{\circ} \mathrm{C}$, stopped as indicated for phosphatidylcholine determinations, and the choline released was then determined as described above.

\section{Phosphatidylglycerol determination}

This procedure was based on the method of Schiefer \& Beutler for quantifying phosphatidylglycerol in amniotic fluid (19). The amount of NADH consumed in the reaction is stoichiometric with the amount of phosphatidylglycerol present in the aqueous sample and is determined from the decrease in absorbance at $340 \mathrm{~nm}$. Briefly, the reaction was carried out in an assay system $(1.1 \mathrm{ml})$ containing $132 \mathrm{mmol} / \mathrm{l}$ sodium borate buffer, $\mathrm{pH} 8.0 ; 5.0 \mathrm{mmol} / \mathrm{l}$ $\mathrm{MgSO}_{4} ; 5.5 \mathrm{~g} / \mathrm{l}$ of Triton X-100; $227 \mu \mathrm{mol} / / \mathrm{NADH} ; 901 \mu \mathrm{mol} / \mathrm{l}$ ATP; $1.9 \mathrm{mmol} / 1$ phosphoenolpyruvate; $2730 \mathrm{U} / \mathrm{h}$ of pyruvate $\mathrm{ki}$ nase; $2730 \mathrm{U} / \mathrm{l}$ of lactate dehydrogenase; $391 \mathrm{U} / 1$ of glycerol kinase and sample or standard up to $0.4 \mathrm{ml}$. The assay system was mixed, incubated at $25^{\circ} \mathrm{C}$ for $20 \mathrm{~min}$, and measured at $340 \mathrm{~nm}\left(\mathrm{~A}_{1}\right)$. Finally, $10 \mu$ l containing $260 \mathrm{kU} / \mathrm{l}$ of phospholipase $\mathrm{D}$ were added to the assay system, mixed, incubated at $25^{\circ} \mathrm{C}$ for $40 \mathrm{~min}$, and measured again at $340 \mathrm{~nm}\left(\mathrm{~A}_{2}\right)$.

In all enzymatic determinations, reagent blanks with water instead of sample were used. Sample blanks were not necessary, because no free alcohol was present in the samples (data not shown).

The amounts of phosphatidylcholine, sphingomyelin or phosphatidylglycerol present in the aqueous samples $(c)$, expressed as $\mu \mathrm{mol} / \mathrm{l}$, were calculated using the following expression:

$$
c=V_{F} \cdot\left[\left(A_{1}-A_{2}\right)_{\text {sample }}-\left(A_{1}-A_{2}\right)_{\text {blank }}\right] / \varepsilon_{340} \cdot b \cdot V_{s}
$$

where $V_{F}=$ final volume of the assay mixture $(0.0011 \mathrm{l})$; $A_{1}-A_{2}=\Delta$ absorbance at $340 \mathrm{~nm} ; \varepsilon_{340}=622 \mathrm{~m}^{2} \cdot \mathrm{mol}^{-1}$; $\mathrm{b}=$ light path $(0.01 \mathrm{~m}) ; \mathrm{V}_{\mathrm{s}}=$ sample volume.

Total phospholipid contents were determined according to Rouser et al. (25) by measuring the lipid phosphorus after hydrolysis of the samples with $\mathrm{HClO}_{4}$. Protein concentrations were determined by the method of Bradford (26) using bovine serum albumin as standard.

\section{Statistical analysis}

Analysis of variance complemented by the Scheffé test was used for statistical analysis. $p$ values $\leq 0.01$ were considered significant.

\section{Results}

\section{Range and detection limit of the assays}

Standard plots, obtained using aqueous dispersions of synthetic dipalmitoyl-sn-glycero-3-phosphocholine (fig. la) and sphingomyelin (fig. 1b), were linear, at least at concentrations between 1.8 and $45.5 \mu \mathrm{mol} / \mathrm{l}$ of assay mixture, with correlation coefficients of 0.99 and slopes of $6.5 \times 10^{-3}$ and $6.1 \times 10^{-3}$, respectively. A decrease in absorbance at $340 \mathrm{~nm}$ of 0.05 units was produced by 7.7 or $8.2 \mu \mathrm{mol} / 1$ of dipalmitoyl-sn-glycero-3-phosphocholine or sphingomyelin in the assay mixture, respectively. Detection limits were at $\Delta \mathrm{A}_{340}=0.010$ \pm 0.002 , corresponding to $1.8 \mu \mathrm{mol}$ of phospholipids per litre of assay. When phosphorylcholine standards of the same molar concentrations as dipalmitoyl-sn-glycero-3-phosphocholine or sphingomyelin standards were assayed, a linear plot that almost overlapped the dipalmitoyl-sn-glycero-3-phosphocholine standard plot was obtained (fig. 1a). In the phosphatidylglycerol determination, the response of the enzymatic method was linear, at least at concentrations between 2.3 and $45.4 \mu \mathrm{mol}$ of dipalmitoyl-sn-glycero-3-phosphoglycerol per litre of the assay, with a correlation coefficient of 0.99 and a slope of $6.7 \times 10^{-3}$ (fig. 1c). A decrease in absorbance at $340 \mathrm{~nm}$ of 0.05 units was produced by the presence of $7.5 \mu \mathrm{mol}$ of dipalmitoyl-sn-glycero-3-phosphoglycerol per litre of the assay. The detection limit of phosphatidylglycerol determination was $2.3 \mu \mathrm{mol} / \mathrm{l}$. Similar data were obtained when glycerol standards of the same molar concentrations as dipalmitoyl-sn-glycero-3-phosphoglycerol were assayed (fig. 1c).

\section{Accuracy of the assays}

The accuracy of the enzymatic methods was assessed by measuring the phosphatidylcholine or sphingomyeline contents of lipid dispersions and membranes from sheep erythrocytes or platelets, and comparing the values obtained with those reported for the same materials using two-dimensional TLC after lipid extraction and inorganic phosphorus determination of the phospholipid spots $(21,23)$. As can be seen in table 1 , all phospholipid species from sheep erythrocytes or platelets showed similar percentages, regardless of the procedures used for their determination. Moreover, the enzymatic analysis afforded basically identical phosphatidylcholine and sphingomyelin concentrations for both lipid dispersions and blood cell membranes. Additionally, we also checked the analytical recovery of 5 different known amounts of dipalmitoyl-sn-glycero-3-phosphocholine, sphingomyelin or dipalmitoyl-sn-glycero-3-phosphoglycerol added to pulmonary surfactant from adult rats, and the levels measured were compared with those expected. Recoveries of 90 to $106 \%, 89$ to $108 \%$, and 92 to $106 \%$ were obtained (data not shown).

\section{Precision}

Within-run imprecision was checked with aliquots from a high-phospholipid pool and a low-phospholipid pool. The SD for the high-dipalmitoyl-sn-glycero-3-phosphocholine, sphingomyelin and dipalmityol-sn-glycero3-phosphoglycerol were $0.9,0.5$ and $0.6 \mu \mathrm{mol} / \mathrm{l}$, with CVs of $2.7,3.0$ and $2.9 \%$, respectively. For the lowdipalmitoyl-sn-glycero-3-phosphocholine, sphingomyelin and dipalmitoyl-sn-glycero-3-phosphoglycerol, the corresponding figures were $0.8,0.6$ and $0.6 \mu \mathrm{mol} / \mathrm{l}$, and $4.3,4.6$ and $4.9 \%$. 


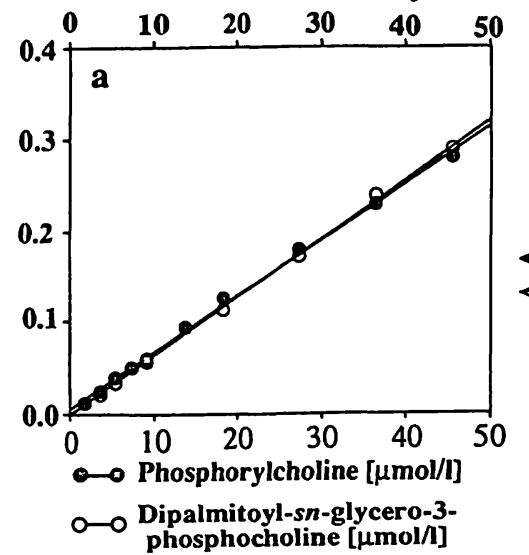

Fig. 1 Standard plots for dipalmityol-sn-glycero-3-phosphocholine $(0-0)$ and phosphorylcholine $(0-0)$ (panel a); sphingomyelin (panel b); dipalmitoyl-sn-glycero-3-phosphoglycerol (o-o), and glycerol $(\bullet-\bullet)$ (panel c) using enzymatic procedures. SDs were alivays less than $4 \%$.

Day-to-day imprecision was checked in 15 assays. The SD for a high- or low-dipalmitoyl-sn-glycero-3-phosphocholine, sphingomyelin and dipalmitoyl-sn-glycero3-phosphoglycerol were $1.3,0.8$ and $1.0 \mu \mathrm{mol} / \mathrm{l}$, and 1.1 , 0.8 and 0.9 , respectively. The CVs were $3.0,3.5$, and $3.3 \%$, and $6.5,6.6$ and $7.0 \%$ for the high and the low pools, respectively.

Phospholipid composition of pulmonary surfactant from rats of different ages, and rats maintained with hyperoxia for two days.

The enzymatic methods described above were used to determine the phospholipid composition of pulmonary surfactant from rats of different ages (tab. 2). The main lipid class was phospholipid $(92-85 \%$, data not shown), and the phospholipid/protein ratios decreased during animal development. The most abundant phospholipid was phosphatidylcholine (80-85\%). The concentration of this species did not change during development. By contrast, the phosphatidylglycerol and sphingomyelin contents of surfactant showed signifi-
Correlations
a) $\bullet \mathrm{y}=-2.0983 \times 10^{-3}+6.4819 \times 10^{-3} \mathrm{x} ; \mathrm{r}^{2}=0.999$
$\circ y=4.9730 \times 10^{-3}+6.2026 \times 10^{-3} \mathrm{x} ; \mathrm{r}^{2}=0.997$
b) $\mathrm{y}=1.0134 \times 10^{-3}+6.1148 \times 10^{-3} \mathrm{x} ; \mathrm{r}^{2}=0.998$
c) $\bullet y=-2.6706 \times 10^{-3}+6.7056 \times 10^{-3} \mathrm{x} ; \mathrm{r}^{2}=0.998$ $\circ y=-1.7668 \times 10^{-3}+6.4847 \times 10^{-3} x ; r^{2}=0.997$

cant variations in animals of different ages, with higher contents of phosphatidylglycerol and lower contents of sphingomyelin in adult animals. Thus, the phosphatidylcholine/phosphatidylglycerol molar ratio was about 5 times lower in adult rat surfactant than in surfactant from newborns, while the phosphatidylglycerol/sphingomyelin molar ratio was about 5 times higher. We also studied the effects of normobaric hyperoxia on the phospholipid composition of pulmonary surfactant from rats of different ages. For these experiments we chose young animals (2 days old) and adults. As shown in table 3, hyperoxia did not significantly modify the phospholipid composition of pulmonary surfactant from 2 days old rats. In contrast, hyperoxia decreased the phosphatidylglycerol content of adult rat surfactant, which led to changes in the phosphatidylcholine/phosphatidylglycerol and phosphatidylglycerol/sphingomyelin molar ratios. The control data to these values were omitted from table 3 for simplification and because they were fully coincident with the values shown in table 2 for the corresponding ages

Tab. 1 Accuracy of phospholipid determination in aqueous dispersions by enzymatic methods. Data are expressed as mean $\pm S D$ of $n$ assays for each group.

Source

Phospholipid contents, fraction of total phospholipids (\%)

\begin{tabular}{|c|c|c|c|}
\hline \multicolumn{2}{|c|}{ Phosphatidylcholine } & \multicolumn{2}{|l|}{ Sphingomyelin } \\
\hline $\begin{array}{l}\text { Enzymatic assay } \\
(\mathrm{n}=10)\end{array}$ & $\begin{array}{l}\text { TLC }{ }^{a} \text { procedure } \\
(n=5)\end{array}$ & $\begin{array}{l}\text { Enzymatic assay } \\
(\mathrm{n}=10)\end{array}$ & $\begin{array}{l}\text { TLC }{ }^{a} \text { procedure } \\
(\mathrm{n}=5)\end{array}$ \\
\hline
\end{tabular}

Sheep platelets

Lipid dispersions

$31.9 \pm 0.1$

Membranes
$28.9 \pm 1.5$

$29.8 \pm 1.3(23)$
$45.5 \pm 0.7$

$43.0 \pm 2.0$
$45.9 \pm 2.3$

$47.3 \pm 2.4(23)$

Sheep erythrocytes

Lipid dispersions

Membranes

a Data obtained by TLC as reported by Marín et al. (21) and Sánchez-Yagüe \& Llanillo (23). 
of the rats. Therefore, the control values are those offered in table 2, as indicated in the legend of table 3.

\section{Discussion}

Several enzymatic methods have been reported for measuring phosphatidylcholine, sphingomyelin and phosphatidylglycerol in body fluids, mainly in amniotic fluid (15-19). These procedures are specific and require less time and sample than conventional methods. We therefore investigated the possibility of using these assays to measure phosphatidylcholine, sphingomyelin and phosphatidylglycerol contents in different biological samples suspended in aqueous solutions.

The specificity of the phosphatidylcholine assay was provided by the combination of phospholipase $\mathrm{C}$ from Bacillus cereus and choline kinase. The overlapping linear plots of dipalmitoyl-sn-glycero-3-phosphocholine and phosphorylcholine standards (fig. 1a) suggest that phosphatidylcholine is completely hydrolysed by phospholipase $\mathrm{C}$ during the first incubation of the reaction mixture. The accuracy of the method was established by comparing the phosphatidylcholine concentrations obtained using the enzymatic method with those obtained using the TLC procedure in both lipid dispersions and cell membranes from sheep erythrocytes and platelets. As can be seen in table 1, the enzymatically measured results were almost identical to the results obtained with the TLC determinations.
A procedure partially based on the phosphatidylcholine enzymatic determination has been developed by us to measure the sphingomyelin contents of aqueous samples. The specificity of the assay was provided by the combination of sphingomyelinase and choline kinase. The similar slopes shown by the linear plots of sphingomyelin and phosphorylcholine standards (figs la and $1 \mathrm{~b}$ ) suggest that sphingomyelin is completely hydrolysed by sphingomyelinase during the first incubation of the reaction mixture. The assay behaves identically to the enzymatic for phosphatidylcholine determination, with $100 \%$ effectiveness in the determination of aqueous samples containing between 1.8 and $45.5 \mu \mathrm{mol}$ of sphingomyelin per litre assay solution. The accuracy of the method was assessed in the same way as that for phosphatidylcholine. The enzymatically measured sphingomyelin concentrations (tab. 1) were $94-102 \%$ of those determined by TLC. Assmann \& Schriewer (18) reported an enzymatic method for the determination of sphingomyelin concentrations in amniotic fluid using prior lipid extraction. However, our procedure permits the measurement of sphingomyelin directly in biological materials suspended in aqueous solutions without prior extraction.

The specificity of the phosphatidylglycerol assay was provided by the combination of phospholipase D from Streptomyces species and glycerol kinase. The data shown in figure 1c are consistent with a total cleavage of phosphatidylglycerol catalysed by phospholipase D to yield glycerol and phosphatidate under the assay con-
Tab. 2 Phospholipid composition of pulmonary surfactant from rats of different ages determinated by enzymatic procedures.
Data are expressed as means \pm SD of 10 assays for each group. In each column, means without coincident superscript letters $(a, b$, c) differ significant by the Scheffé test $(\mathrm{p} \leq 0.01)$.

\begin{tabular}{|c|c|c|c|c|c|c|c|}
\hline \multirow[t]{2}{*}{$\begin{array}{l}\text { Rat } \\
\text { age }\end{array}$} & \multirow{2}{*}{$\begin{array}{l}\text { Phospholipid/ } \\
\text { protein ratio } \\
\text { (mg/mg) }\end{array}$} & \multicolumn{3}{|c|}{$\begin{array}{l}\text { Phospholipid composition, } \\
\text { fraction of total phospholipids (\%) }\end{array}$} & \multicolumn{3}{|c|}{ Phospholipid molar ratio } \\
\hline & & $\mathrm{PC}$ & SM & PG & $\mathrm{PC} / \mathrm{SM}$ & $\mathrm{PG} / \mathrm{SM}$ & $\mathrm{PC} / \mathrm{PG}$ \\
\hline $\begin{array}{l}\text { Newborns } \\
2 \text { Days } \\
7 \text { Days } \\
\text { Adults }\end{array}$ & $\begin{array}{l}4.5 \pm 0.3^{\mathrm{a}} \\
2.5 \pm 0.6^{\mathrm{b}} \\
1.5 \pm 0.1^{\mathrm{b}} \\
0.3 \pm 0.2^{\mathrm{c}}\end{array}$ & $\begin{array}{l}84.6 \pm 6.1^{\mathrm{a}} \\
76.3 \pm 7.9^{\mathrm{a}} \\
79.4 \pm 7.5^{\mathrm{a}} \\
80.5 \pm 6.5^{\mathrm{a}}\end{array}$ & $\begin{array}{l}3.8 \pm 0.5^{\mathrm{a}} \\
5.2 \pm 2.4^{\mathrm{a}} \\
2.1 \pm 0.8^{\mathrm{b}} \\
2.7 \pm 0.6^{\mathrm{ab}}\end{array}$ & $\begin{array}{l}1.6 \pm 4.0^{\mathrm{a}} \\
4.4 \pm 1.7^{\mathrm{a}} \\
1.6 \pm 0.4^{\mathrm{a}} \\
5.8 \pm 1.9^{\mathrm{b}}\end{array}$ & $\begin{array}{l}21.7 \pm 4.0^{\mathrm{ab}} \\
21.2 \pm 3.0^{\mathrm{a}} \\
40.4 \pm 9.3^{\mathrm{b}} \\
31.3 \pm 9.7^{\mathrm{ab}}\end{array}$ & $\begin{array}{l}0.41 \pm 0.10^{\mathrm{a}} \\
0.85 \pm 0.70^{\mathrm{a}} \\
0.72 \pm 0.40^{\mathrm{a}} \\
2.6 \pm 0.7^{\mathrm{b}}\end{array}$ & $\begin{array}{l}56.0 \pm 10.5^{\mathrm{a}} \\
17.4 \pm 10.0^{\mathrm{a}} \\
49.5 \pm 19.6^{\mathrm{a}} \\
11.4 \pm 3.7^{\mathrm{b}}\end{array}$ \\
\hline
\end{tabular}

PC: phosphatidylcholine; PG: phosphatidylglycerol; SM: sphingomyelin.

Tab. 3 Phospholipid composition of pulmonary surfactant from rats maintained under hyperoxia for 2 days, determined by enzymatic procedures.
Data are expressed as means $\pm S D$ of 10 assays for each group. Asterisks represent significant differences [Scheffé test $(p \leq 0.01)$ ] when values shown here are compared with values from the respective control groups (rats breathing air, values shown in table 2).

\begin{tabular}{|c|c|c|c|c|c|c|c|}
\hline \multirow[t]{2}{*}{$\begin{array}{l}\text { Rat } \\
\text { age }\end{array}$} & \multirow{2}{*}{$\begin{array}{l}\text { Phospholipid/ } \\
\text { protein ratio } \\
(\mathrm{mg} / \mathrm{mg})\end{array}$} & \multicolumn{3}{|c|}{$\begin{array}{l}\text { Phospholipid composition, } \\
\text { fraction of total phospholipids (\%) }\end{array}$} & \multicolumn{3}{|c|}{ Phospholipid molar ratio } \\
\hline & & PC & SM & PG & $\mathrm{PC} / \mathrm{SM}$ & PG/SM & PC/PG \\
\hline $\begin{array}{l}2 \text { Days } \\
\text { Adults }\end{array}$ & $\begin{array}{l}2.5 \pm 0.2 \\
0.3 \pm 0.1\end{array}$ & $\begin{array}{l}70.5 \pm 4.5 \\
76.0 \pm 8.2\end{array}$ & $\begin{array}{l}1.9 \pm 0.6 \\
4.2 \pm 1.6\end{array}$ & $\begin{array}{l}7.0 \pm 2.4 \\
1.3 \pm 0.3^{*}\end{array}$ & $\begin{array}{l}36.0 \pm 6.5 \\
28.4 \pm 10.1\end{array}$ & $\begin{array}{l}3.0 \pm 1.3 \\
0.4 \pm 0.2^{*}\end{array}$ & $\begin{array}{l}14.1 \pm 5.7 \\
77 \pm 22.1^{*}\end{array}$ \\
\hline
\end{tabular}

PC: phosphatidylcholine; PG: phosphatidylglycerol; SM: sphingomyelin. 
ditions. Here, we report similar decreases in absorbances at $340 \mathrm{~nm}$ for equivalent amounts of dipalmitoyl-snglycero-3-phosphoglycerol and glycerol, with almost identical values to those observed in reactions containing equivalent amounts of phosphatidylcholine and sphingomyelin. It may therefore be concluded that the total amounts of NADH consumed in the reactions are stoichiometric with the amount of phosphatidylglycerol, phosphatidylcholine or sphingomyelin, and that the assay conditions allow full quantification of the phospholipids present in the sample. The accuracy of the phosphatidylglycerol determination could only be assessed by using pulmonary surfactant from rats of different ages, because phosphatidylglycerol contents in blood cells were very low, and by comparing our phosphatidylglycerol values with published data using other methods. The phosphatidylglycerol values $(6 \%$ of total phospholipids) obtained from adult rats are very similar to those previously published (27-29).

Additionally, the analytical recoveries for various amounts of exogenous phosphatidylcholine, sphingomyelin and phosphatidylglycerol added to surfactant samples from adult rats were always between $89-108 \%$ (see Results), thus confirming the accuracy of the methods.

The methods discussed above have been used to study the phospholipid composition of dialysed bronchoalveolar lavage fluids from rats of different ages. It is important that surfactant should be dialysed prior to enzymatic assay to prevent non-specific interfering reactions, in particular to avoid potential interference from endogenous biochemicals such as glycerol and choline. We were able to perform this study owing to the small amount of sample necessary to carry out the assay. Phospholipid/protein ratios showed a gradual decrease during animal development, as reported previously (30). In adults, this ratio was lower than previously published (29), possibly due to contamination of the bronchoalveolar lavage fluid by plasma proteins $(31,32)$. Nevertheless, this did not modify the phospholipid profile, as can be deduced from the data shown in table 2, which are very similar to those published previously (27-29). Accordingly, determination of phospholipid profiles does not seem to require the purification of surfactants from associated proteins, with a consequent saving of analysis time.

The phospholipid composition of rat pulmonary surfactant underwent significant variations during development. Phosphatidylcholine is the main phospholipid responsible for the generation of the low surface tension found in the contracted lung (33). The content of phosphatidylcholine as well as that of total phospholipids in rat lung increase sharply during the later stages of fetal development, when adult levels are reached (34). This correlates well with the non-significant changes detected in phosphatidylcholine contents by us in this work, and by others $(29,34)$. In contrast, phosphatidylglycerol levels rose from $2 \%$ in newborns to $6 \%$ in adult rats (tab. 2), resulting in an increase in the phosphatidylcholine/ sphingomyelin and phosphatidylglycerol/sphingomyelin ratios, with a concomitant decrease in the phosphatidylcholine/phosphatidylglycerol ratio. The phosphatidylcholine/phosphatidylglycerol ratio in adult rats coincides with data previously reported (35). The development of the phospholipid profile in pulmonary surfactant is well correlated with the developmental increase shown by the enzymes of pulmonary desaturated phosphatidylcholine and phosphatidylglycerol synthesis measured in different species during fetal and early postnatal life (4).

It has been reported that an increased production of oxygen radicals in lung cells is a major factor in the aetiology of lung damage during hyperoxia. In our study, we observed that hyperoxia seems to affect the phospholipid composition of pulmonary surfactant differently, depending on the age of the rat. Thus, we were able to detect phospholipid modifications in surfactant only in adult rats, but not in 2 days old rats. In adult rats, the phosphatidylglycerol content decreased from $5.8 \%$ to $1.3 \%$, when the animals were exposed to normobaric hyperoxia for 2 days prior to sacrifice. This change could contribute to lethal respiratory pathology. The phosphatidylcholine content was not affected by hyperoxia, in agreement with previous data (36).

\section{Conclusion}

We conclude that the enzmatic methods described here are much more sensitive than conventional procedures based on the separation of phospholipids by TLC and their quantification by measuring their phosphorus contents. Two dimensional TLC requires about 320 nmol of total phospholipid to visualize the individual phospholipids (23). Nevertheless, it should be noted that the use of special mobile phases containing triethylamine in one-dimensional high performance TLC/densitometry allows complete separation of the six major phospholipids present in amniotic fluid, with similar detection limits to those reported here, but requires a prior lipid extraction step (11). On the other hand, our enzymatic methods can be applied directly to aqueous samples of membranes, body fluids and other biological materials without previous lipid extraction. Moreover, they are accurate, relatively easy to perform and require less time and sample than conventional methods, offering a reliable alternative for the determination of the phospholipid composition of different types of aqueous samples. 


\section{References}

1. Kent C, Carmen GM, Spence MW, Dowhon W. Regulation of eukaryotic phospholipid metabolism. FASEB J 1991; 5:2258-66.

2. Post M, Van Golde LMG. Metabolic and developmental aspects of the pulmonary surfactant system. Biochim Biophys Acta 1988; 947:249-86.

3. Hallman M. Antenatal diagnosis of lung maturity. In: Robertson B, Van Golde LMG, Batenburg JJ, editors. Pulmonary surfactant. Amsterdam: Elsevier Publishers, 1984:419-47.

4. Rooney SA. Lung surfactant. Environ Health Perp 1984; 55:205-26.

5. Nöe C, Marcel YL, Davignon J. Plasma phospholipids in the different types of primary hyperlipoproteinemia. J Lab Clin Med 1972; 79:611-21.

6. Turner JD, Rouser G. Precise quantitative determination of human blood lipids by thin-layer and triethylaminoethylcellulose column chromatography. I. Erythrocyte lipids. Anal Biochem $1970 ; 8: 423-36$.

7. Gluck L, Kulovich MV, Borer RCJr, Brenner PH, Anderson GG, Spellacy WN. Diagnosis of respiratory distress syndrome by amniocentesis. Am J Obstet Gynecol 1971; 109:440-7.

8. Moore $P$. The lecithin-sphingomyelin ratio in amniotic fluid by thin layer chromatography: three areas of difficulty. Med Lab Sci 1982; 39:237-44.

9. Painter PC. Simultaneous measurement of lecithin, sphingomyelin, phosphatidylglycerol, phosphatidylinositol, phosphatidylethanolamine and phosphatidylserine in amniotic fluid. Clin Chem 1980; 26:1147-51.

10. Oulton M, MacDonald J, Tanigan DT, Faulkner GT. Mouse alveolar surfactant: characterization of subtypes prepared by differential centrifugation. Lipids 1993; 28:715-20.

11. Touchstone JC, Chen JC, Beaver KM. Improved separation of phospholipids in thin layer chromatography. Lipids 1980; 15:61-2.

12. Jungalwala FB, Evans JE, Cluer RH. High-performance liquid chromatography of phosphatidylcholine and sphingomyelin with detection in the region of $200 \mathrm{~nm}$. Biochem J 1976; 155:55-60.

13. Bonano LM; Denizot BA, Tchoreloff PC, Puisieux F, Cardot PJ. Determination of phospholipids from pulmonary surfactant using an on-line coupled silica/reversed-phase high-performance liquid chromatography system. Anal Chem 1992; 64:371-9.

14. Mueller RG. Effect of charring temperature on observed L/S ratio. Clin Chim Acta 1982; 122:79-83.

15. Dubin SB. The laboratory assessment of fetal lung maturity. Am J Clin Pathol 1992; 97:836-49.

16. Anaokar S, Garry PJ, Standefer JC. Enzymic assay for lecithin in amniotic fluid. Clin Chem 1978; 25:103-7.

17. Schiefer S, Beutler HO. Phosphatidylcholine (Lecithin). In: Bergmeyer J, Graßl M, editors. Methods of enzymatic analysis. Metabolites 3: lipids, aminoacids and related compounds. 3rd ed. Weinheim (Germany): VCH Publishers, 1985; 8:87-104.

18. Assmann G, Schriewer $H$. Sphingomyelin. In: Bergmeyer J, Graßl M, editors. Methods of enzymatic analysis. Metabolites 3: lipids, aminoacids and related compounds. 3rd ed. Weinheim (Germany): VCH Publishers, 1985; 8:105-11.

19. Schiefer S, Beutler HO, Phosphatidylglycerol. In: Bergmeyer J, Graßl M, editors. Methods of enzymatic analysis. Metabolites 3: lipids, aminoacids and related compounds. 3rd ed. Weinheim (Germany): VCH Publishers, 1985; 8:117-25.
20. Sánchez-Yagüe J, Cabezas JA, Llanillo M. Subcellular distribution and characterization of acetylcholinesterase activities from shcep platelets: relationship between temperature-dependence and environment. Blood 1990; 76:737-44.

21. Marín MS, Fernández A, Sánchez-Yagüe J, Cabezas JA, Llanillo $\mathrm{M}$. Changes in the phospholipid and fatty acid composition in normal erythrocytcs from sheep of different ages. Aminophospholipid organization in the mombrane bilayer. Biochimie 1990; 72:745-50.

22. Bligh EG, Dyer WJ. A rapid method of total lipid extraction and purification. Can J Biochem Physiol 1959; 37:911-5.

23. Sánchez-Yagüe J, Llanillo M. Lipid composition of subcellular particles from sheep platelets. Location of phosphatidylethanolamine and phosphatidylserine in plasma membranes and platelet liposomes. Biochim Biophys Acta 1986; 856:193-201.

24. Rose HG, Oklander M. Improved procedure for the extraction of lipids from human erythrocytes. J Lipid Res 1965; $6: 428-31$.

25. Rouser AJ, Fleischer S, Yamamoto A. Two dimensional thinlayer chromatographic separation of polar lipids and determination of phospholipids by phosphorus analysis of spots. Lipids 1970; 5:494-6.

26. Bradford MM. A rapid and sensitive method for the quantification of microgram quantitics of protein utilizing the principle of protein-dye binding. Anal Biochem 1976; 72:248-54.

27. Harwood JL, Desai R, Hext P, Tetley T, Richards R. Characterization of pulmonary surfactant from ox, rabbit, rat and sheep. Biochem J 1975: 151:707-14.

28. Adachi H, Hayashi H, Sato H, Dempo K, Akino T. Characterization of phospholipids accumulated in pulmonary surfactant compartments of rats intratracheally exposed to silica. Biochem J 1989; 262:781-6.

29. Katya SL, Estes DLW, Lombardi B. Method for the isolation of surfactant from homogenates and lavages of lung of adult, newborn, and fetal rats. Lab Invest 1977; 36:585-92.

30. Benson BJ, Kitterman JA, Clements JA, Mescher EJ, Tooley WH. Changes in phospholipid composition of lung surfactant during development in the fetal lamb. Biochim Biophys Acta 1983; 753:83-8.

31. Bignon J, Jaurand MC, Pinchon MC, Sapin C, Warnet JM. Immunoelectron microscopic and immunochemical demonstrations of serum protein in the alveolar lining material of the rat lung. Am Rev Des Dis 1976; 113:109-20.

32. Hawgood S, Shiffer K. Structures and properties of the surfactant-associated proteins. Ann Rev Physiol 1991; 53:375-94.

33. Dobbs LG. Pulmonary surfactant. Ann Rev Med 1989; 40:431-46.

34. Okano G, Akino T. Changes in the structural and metabolic heterogeneity of phosphatidylcholines in the developing rat lung. Biochim Biophys Acta 1978; 528:373-84.

35. Shelley SA, Paciga JE, Balis JU. Lung surfactant phospholipids in different animal species. Lipids 1984; 19:857-62.

36. Abe $M$, Tierney DF. Lipid metabolism of rat lung during recovery from lung injury. Fed Proc 1976; 35:479-82.

\section{Received August 4/October 12, 1995}

Corresponding author: Dr. Marcial Llanillo, Departamento de Bioquímica y Biología Molecular, Edificio Departamental, Lab. 106, Avda. del Campo Charro s/n, E-37007 Salamanca. Spain 
' 